and separated from the plaster. In this medium granulations rapidly form, and $\mathrm{Carty}^{9}$ has observed their rapid growth in three large deep ulcers where previous forms of treatment had been unavailing. There is as yet no consensus of opinion as to the agent responsible for this acceleration of healing under the occlusive dressing.

\section{Results of Occlusive Treatment}

The method as applied to this small series has been remarkably satisfactory. Cases have been treated and released for duty immediately, while almost instantaneous relief of pain has been afforded.

A summary of the results can be seen from the accompanying table:

$\begin{array}{ccc}\text { Number of } & \text { Average Number } & \text { Average Number of } \\ \text { Cases } & \text { of Dressings } & \text { Days under Treatment } \\ 20 & 2-3 & 11-12\end{array}$

Only one case received hospital treatment, and that on account of the unique patchwork appearance presented by the multitude of occlusive dressings on his neck. He was treated by the usual method, the dressings remaining untouched as before. One case received adjuvant treatment in the form of collosol manganese.

Many other septic conditions-for example, whitlows, lymphangitis, ulcers, burns, etc.-have been successfully treated by the method described, but they have not been included in the cases reviewed.

REFERENCES

1 Newman: British Medical Journal, 1933, i, 823.

2 Orr, Winnett: Ibid., 1933, ii, 365.

3 Donald: Ibid., 1935, i, 964.

Walton: Lancet 1930, ii, 1073

- Dixon: British Medical Journal, 1935. i, 152.

- Robb: Ibid., 1935, i, 466.

"Strauss: Deut. med. Woch., January 11th, 1935, p. 50

- Schimer: Amer. Journ. Surg., 1934, xxiii, 195.

- Carty: British Medical Journal, 1935, i, 105.

\section{PRIMARY AXILLARY VEIN THROMBOSIS} BY

A. D. BELILIOS, M.B., B.S.Lond., D.P.H. HONORARY MEDICAL OFFICER, WIMBLEDON HOSPITAL AND

\section{A. W. J. HOUGHTON, M.B., B.S.LoND.,} RESIDENT MEDICAL OFFICER, WIMBLEDON HOSPITAL

Thrombosis of the axillary vein, without history of injury or infection, appears to be a rare condition ; but only one example can be found in the literature of the occurrence of thrombosis in both axillary veins, and it is for this reason that the following case is described.

\section{Case Report}

The patient, a healthy man aged 24 years, is employed as a labourer in an electric lamp factory. $\mathrm{He}$ is ambidextrous, but prefers to use his left hand whenever possible. At the time of the first attack he was engaged in delivering the components of batteries from a machine by the use of his left hand and then passing them on to a shelf at his left side. This process necessitated repeated abduction of the arm. About a month before the acute attack he noticed that when lifting a heavy object his left arm felt tense and became swollen and blue. Moreover, if he continued to hold the weight above the ievel of his shoulder the condition rapidly became worse, but was relieved on adduction of the arm. Suddenly, in October, 1933, during a game of billiards, he discovered that his arm was becoming stiff, swollen, and discoloured; at the same time he experienced giddiness, and fainted immediately on arrival, after two minutes' walk, at his home.
On examination, soon after onset, the whole of the left upper extremity was found to be swollen, cyanosed, and cold, the physical signs corresponding with the second attack as described below. $\mathrm{He}$ was treated in hospital by complete rest and immobilization, and made an uninterrupted recovery within three weeks.

The next attack occurred on May 7th, 1935, and involved the right arm, but no history of prodromal symptoms could be obtained on this occasion. In the meantime he had changed his work, which now consisted of shaking lamps after they had been washed and then placing them on a shelf by his side, the process involving the use of both arms. On this occasion he was walking along a road, two days after beginning a holiday from work, when his right arm became suddenly swollen, cold, and blue, and felt first " tight," then " numb." $\mathrm{He}$ complained of giddiness as before, and attended an ambulance station, from which he was brought immediately to hospital.

On examination the right upper extremity was swollen and oedematous, the patient supporting it with his left arm. Passive and active movements were limited and very painful. The axillary vein could be palpated as a series of soft and tender swellings. All swelling and oedema of the limb ceased abruptly by a sharp line of demarcation at the level of the clavicle. The pulse was present at the wrist and equal in rate to that of the left side, while the blood pressure was $120 / 90$ and equal on both sides.

$\mathrm{He}$ was admitted to a surgical ward, the limb immobilized on a splint, and a dressing of glycerin and ichthyol applied. Within three days the swelling showed considerable reduction, and the patient made a rapid and uneventful recovery. Three weeks later all oedema had disappeared, but distended veins were present in the regions of the anterior axillary fold and back of the shoulder, presumably the development of a collateral venous return.

Nothing abnormal was discovered by the usual pathological investigations, kindly undertaken by Dr. Frank Knott, the Wassermann reaction being negative and the blood calcium 9.2 per cent. The blood count was as follows: red cells, 4,750,000; white cells, 6,020; haemoglobin, 90 per cent.; colour index, 0.95. Differential count: polymorphs, 57 per cent.; lymphocytes, 30 per cent.; hyaline, 9 per cent. ; eosinophils, 3 per cent. ; basophils, 1 per cent. ; platelets, normal. The $x$-ray appearance of the whole shoulder girdle and cervical and upper thoracic vertebrae was likewise normal.

This case falls into line with those hitherto described by Pearce Gould and Patey, ${ }^{1}$ and by B. Horton, ${ }^{2}$ in that the subject was a young healthy male and that the disturbance was probably occasioned by exertion. Moreover, the first attack involved the left arm in a man who preferred to use his left arm. The only left-sided example in Gould and Patey's series was a left-handed man, and occurred while playing golf.

Firth and Mackay ${ }^{3}$ in 1932 reported a case of axillary thrombosis in a girl, occurring first in the right arm and then, after an interval of eighteen months, in the left. The time interval between the two attacks-in the one case eighteen months and in the other twenty-one months-shows remarkable similarity.

Lowenstein's ${ }^{4}$ theory as to causation appears to be the most satisfactory. He demonstrated that in a number of cases the axillary vein is pressed upon by the costocoracoid membrane and the subclavius muscle when the arm is abducted. And in this case, for some weeks prior to the first attack, swelling could be induced by abduction of the arm. Pearce Gould and Patey demonstrated, by dissection, a competent valve at this point.

The clinical picture of a sudden, painful, and cyanosed swelling of the whole upper extremity in a young healthy adult cannot be mistaken.

\section{REFERENCES}

${ }^{1}$ Gould and Patey: Brit. Journ. Surg., 1928, xvi, 208.

2 Horton, B. Journ. Amer. Med. Assoc. 1931, xcvi, 2194.

2 Horton, B.: Journ. Amer. Med. Assoc.,
3. Firth and Mackay: Lancet, 1932, ii, 679 .

- Lowenstein, P. S.: Journ. Amer. Med. Assoc., 1924, clxxxii, 854. 